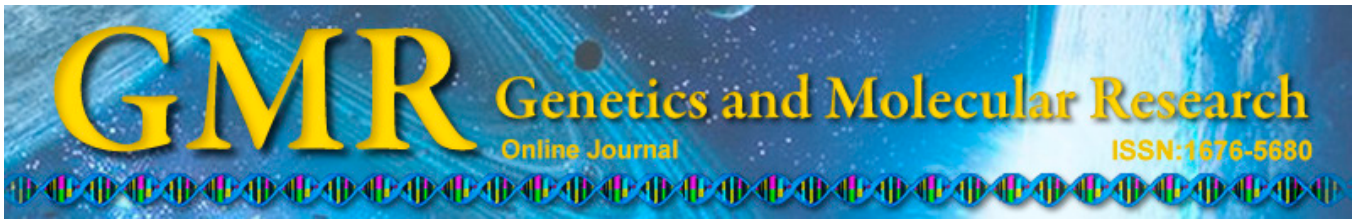

\title{
Impact and significance of EGCG on Smad, ERK, and $\beta$-catenin pathways in transdifferentiation of renal tubular epithelial cells
}

\author{
C.G. Zhao ${ }^{1}$, P. Zhou' ${ }^{2}$ and Y.B. Wu ${ }^{1}$ \\ 'Department of Pediatric Nephrology and Rheumatology, \\ Shengjing Hospital of China Medical University, Shenyang, China \\ ${ }^{2}$ Department of Pediatric Internal Medicine, \\ The Second Affiliated Hospital of Harbin Medical University, Harbin, China \\ Corresponding author: Y.B. Wu \\ E-mail: gczpcn@163.com
}

Genet. Mol. Res. 14 (1): 2551-2560 (2015)

Received March 6, 2014

Accepted July 2, 2014

Published March 30, 2015

DOI http://dx.doi.org/10.4238/2015.March.30.14

\begin{abstract}
We investigated the impact and signal transduction mechanisms of epigallocatechin-3-gallate (EGCG) on transdifferentiation of renal tubular epithelial cells. Rat renal tubular epithelial cells (NRK-52E) were randomly divided into a normal control group, transforming growth factor (TGF)- $\beta 1$-induced group $(10 \mathrm{ng} / \mathrm{mL})$, and intervention groups with $200 \mu \mathrm{g} / \mathrm{L}$ EGCG $+10 \mathrm{ng} / \mathrm{mL}$ TGF- $\beta 1$ and 400 $\mu \mathrm{g} / \mathrm{L}$ EGCG $+10 \mathrm{ng} / \mathrm{mL}$ TGF- $\beta 1$. Tested cells were collected after 48 h. Levels of $\alpha$-smooth muscle actin ( $\alpha$-SMA) and cytokeratin-18 were detected using immunohistochemical methods. Western blotting was used to detect cytoplasmic Pi-extracellular receptor kinase 1/2 (ERK1/2), Pi-Smad 3 protein, and nuclear $\beta$-catenin protein. mRNA expression of $E R K 2, S m a d 3$, and $\beta$-catenin was measured by reverse transcriptionpolymerase chain reaction. After induction by TGF- $\beta 1$, cytokeratin-18 expression in the renal tubular epithelial cells decreased and $\alpha$-SMA
\end{abstract}


expression appeared. mRNA expression of cytoplasmic $P i-S m a d 3$ and Pi-ERK1/2, Smad3, ERK2, and $\beta$-catenin protein expression increased, while $\beta$-catenin mRNA decreased. These changes were reduced after intervention by EGCG. EGCG may be helpful for maintaining the renal tubular epithelial cell phenotype and reducing the degree of TGF- $\beta 1$ induced cell transdifferentiation, which may be related to the signal transduction pathway of ERK, Smad3, and $\beta$-catenin.

Key words: $\alpha$-Smooth muscle actin; Cytokeratin-18; Epithelial cells; Epigallocatechin-3-gallate; Transforming growth factor

\section{INTRODUCTION}

The epithelial mesenchymal transdifferentiation (EMT) of tubular epithelial cells (TECs) is an important component of renal interstitial fibrosis. EMT is a process during which fully differentiated epithelial cells undergo a phenotypic change to fibroblasts through diverse intracellular signaling pathways (Kim et al., 2013a). Approximately $36 \%$ of the renal tubule cells in renal interstitial fibroblasts are derived from local EMT when renal interstitial fibrosis occurs (Liu, 2010). Cytokeratin-18 (CK-18) is a marker for the occurrence of transdifferentiation of epithelial cells, while $\alpha$-smooth muscle actin ( $\alpha$-SMA) is a marker for the appearance of mesenchymal cells. As a recognized pro-fibrotic factor, transforming growth factor- $\beta 1$ (TGF- $\beta 1$ ) can stimulate the transformation of mesenchymal cells to epithelial cells (Rastaldi, 2006; García-Sánchez et al., 2010; Zeisberg and Duffield, 2010). EMT in the kidneys is driven by regulation of the expression of fibrogenic cytokines such as TGF- $\beta$ (Liu et al., 2012). The development of effective drugs for preventing and treating fibrosis is difficult and has attracted attention in recent studies.

Epigallocatechin-3-gallate (EGCG) was found to have a role in anti-hepatic fibrosis (Nakamuta et al., 2005; Yumei et al., 2006; Zhen et al., 2007) as well as in reducing oxidative stress and inflammatory factors, and these effects were associated with pathways such as TGF/ Smad and PI3 K/Akt/FoxO1 (Xiao et al., 2013). Whether or not EGCG inhibits the transdifferentiation of renal tubular epithelial cells and the mechanism of this process have not been reported.

In this study, TGF- $\beta 1$ was used to induce the transdifferentiation of rat renal tubular epithelial cell (RTEC) line NRK cells. EGCG was used to intervene with the transdifferentiation process of NRK cells. The role of EGCG on TEC transdifferentiation and the signal transduction mechanisms were evaluated by detecting changes in the expression of CK-18, $\alpha$-SMA and phosphorylated extracellular receptor kinase 1/2 (Pi-ERK1/2), phosphorylated Smad3 (Pi-Smad3), and nuclear $\beta$-catenin in NRK cells.

\section{MATERIAL AND METHODS}

\section{Cell culture and grouping}

Rat RTECs (NRK-52E) were purchased from the Type Culture Collection cell bank of the Sciences Committee of Chinese Academy, established by the American Type Culture Collection. L-EGCG was purchased from Sigma (St. Louis, MO, USA) and TGF- $\beta 1$ was purchased from Peprotech Company (Rocky Hill, NJ, USA). NRK-52E rat RTECs were routinely 
cultured, synchronously treated with serum-free Dulbecco's modified Eagle's medium for 24 $\mathrm{h}$, and then the cultured cells were randomly divided into 4 groups: the normal control group (taking the medium culture solution as a blank control), the TGF- $\beta 1$-induced group ( $10 \mathrm{ng} / \mathrm{mL}$ TGF- $\beta 1$ in the culture medium), the $200 \mu \mathrm{g} / \mathrm{L}$ EGCG intervention group (10 $\mathrm{ng} / \mathrm{mL}$ TGF- $\beta 1$ and $200 \mu \mathrm{g} / \mathrm{L}$ EGCG in culture medium), and the $400 \mu \mathrm{g} / \mathrm{L}$ EGCG intervention group (10 ng/ $\mathrm{mL}$ TGF- $\beta 1$ and $400 \mu \mathrm{g} / \mathrm{L}$ EGCG in the culture medium). Cells in each group were collected for testing after treatment for $48 \mathrm{~h}$.

\section{Immunohistochemical determination of cells climbing slices}

Paraformaldehyde (4\%) was purchased from Sigma. $\alpha$-SMA and CK-18 rabbit antirat antibodies were purchased from Santa Cruz Biotechnology Company (Santa Cruz, CA, USA). The SP immunohistochemical-staining kit and DAB reagent were purchased from Beijing Zhongshan Jinqiao Biotechnology (Beijing, China). Cell climbing slices were washed with phosphate-buffered saline, and then fixed in $4 \%$ paraformaldehyde and stored at $-20^{\circ} \mathrm{C}$. An immunohistochemical method was used to detect $\alpha$-SMA and CK-18. Eight fields of view of each set of pictures were selected. The average optical density values were measured using an Olympus camera system and the MetaMorph/BX41 image data analysis system (Olympus Corporation, Tokyo, Japan). A larger mean optical density value indicated higher target protein content in the representative samples.

\section{Western blotting analysis of cells}

Differential centrifugation was used to extract nuclear proteins and cytoplasmic proteins. Pi-ERK1/2, Pi-Smad3, and $\beta$-catenin-specific antibodies (primary antibodies) were purchased from Cell Signaling Technology Company (Danvers, MA, USA). Equipment such as the Centrifuge 5417R type low-temperature high-speed centrifuge (Eppendorf, Hamburg, Germany), electrophoresis tank (Miniprotein Bio-Rad, Hercules, CA, USA), and transfer film equipment (Trans-blot Cell; Bio-Rad) were used.

Cytoplasmic levels of Pi-ERK1/2, Pi-Smad3, and nuclear $\beta$-catenin were analyzed. Absorbance scanning was analyzed by Flour Chem V 2.0 using the gel image analysis software (ProteinSimple, Santa Clara, CA, USA). $\beta$-actin was included on the same film as an internal reference, and protein content was expressed based on the absorbance ratio of the target protein and the internal reference. A larger ratio indicated higher protein content.

\section{Relative mRNA expression of ERK1/2, Smad3, and $\beta$-catenin determined by real-time polymerase chain reaction (PCR)}

Trizol total RNA extraction solution was purchased from Shanghai Sangon Biological Engineering Co., Ltd. (Shanghai, China). PrimeScript RT Reagent Kit and the real-time quantitative PCR (SYBRRPremix Ex Taq) kit were purchased from TaKaRa (Shiga, Japan). The ABI7500 system was used for quantitative PCR (Invitrogen, Foster City, CA, USA). Total cellular RNA was extracted and reverse transcribed using synthetic primers to cDNA using real-time quantitative PCR; primer sequences are shown in Table 1. The SYBR Green I fluorescent dye-embedded method was used to prepare the standard curve of the target gene and housekeeping gene [glyceraldehyde 3-phosphate dehydrogenase (GAPDH)], which was used 
to quantify the target gene and housekeeping gene in the samples. The relative expression of the target gene in each group was determined by comparison with the housekeeping gene.

\begin{tabular}{|c|c|}
\hline ERK2-F & 5'-CGTTCAGATGTCGGTGTC-3' \\
\hline ERK2-R & 5'-AAAGGAGTCAAGAGTGGG-3' \\
\hline Smad3-F & 5'-GATGCTTCGTGACATTGGAACCTA-3' \\
\hline Smad3-R & 5'-TTCCCACGTTTAAATGCTGCTG-3' \\
\hline$\beta$-catenin-F & 5'-CCCCAAGCCTTAGTAAACA-3' \\
\hline$\beta$-catenin-R & 5'-GACAGACAGCACCTTCAGC-3' \\
\hline GAPDH-F & 5'-GCACCGTCAAGGCTGAGAAC-3' \\
\hline GAPDH-R & 5'-ATGGTGGTGAAGACGCCAGT-3' \\
\hline
\end{tabular}

\section{Statistical analysis}

Data were analyzed using the SPSS 15.0 statistical software (SPSS, Inc., Chicago, IL, USA). Measurement data are reported as means \pm standard deviation. One-way analysis of variance was used for normally distributed data that showed homogeneity of variance. Comparisons between the 2 groups were performed using the $q$-test. $\mathrm{P}<0.05$ indicated statistical significance.

\section{RESULTS}

\section{Protein expression changes of CK-18 and $\alpha$-SMA in NRK cells}

CK-18 in NRK cells was highly expressed in the control group, while $\alpha$-SMA was not expressed. After induction for $48 \mathrm{~h}$, the expression of cytosolic CK-18 protein in NRK cells decreased and the expression of $\alpha$-SMA protein increased. After treating NRK cells with TGF- $\beta 1$ combined with EGCG for $48 \mathrm{~h}, \mathrm{CK}-18$ protein expression in the cytoplasm clearly decreased, and $\alpha$-SMA protein expression was lower than that in the TGF- $\beta 1$-induced group (Table 2 and Figure 1).

\begin{tabular}{|c|c|c|}
\hline$\overline{\text { Group }}$ & CK-18 & $\alpha$-SMA \\
\hline Control group & $0.671 \pm 0.024$ & 0 \\
\hline TGF- $\beta 1$-induced group & $0.225 \pm 0.056^{*}$ & $0.857 \pm 0.045$ \\
\hline EGCG intervention group $(400 \mu \mathrm{g} / \mathrm{L})$ & $0.531 \pm 0.078^{\#}$ & $0.342 \pm 0.028^{*}$ \\
\hline
\end{tabular}

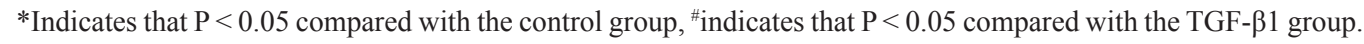

\section{Pi-Smad3 protein and Smad3 mRNA expression in the cytoplasm of NRK cells}

After NRK cells were induced by TGF- $\beta 1$ for $48 \mathrm{~h}$, Pi-Smad3 protein and Smad3 mRNA expression significantly increased. After treatment of NRK cells with TGF- $\beta 1$ and EGCG, these changes were reduced. The effect of alleviating the proteins and mRNA expression by EGCG with a concentration of $400 \mu \mathrm{g} / \mathrm{L}$ was better than that observed when using a concentration of $200 \mu \mathrm{g} / \mathrm{L}$ (Table 3 and Figure 2). 


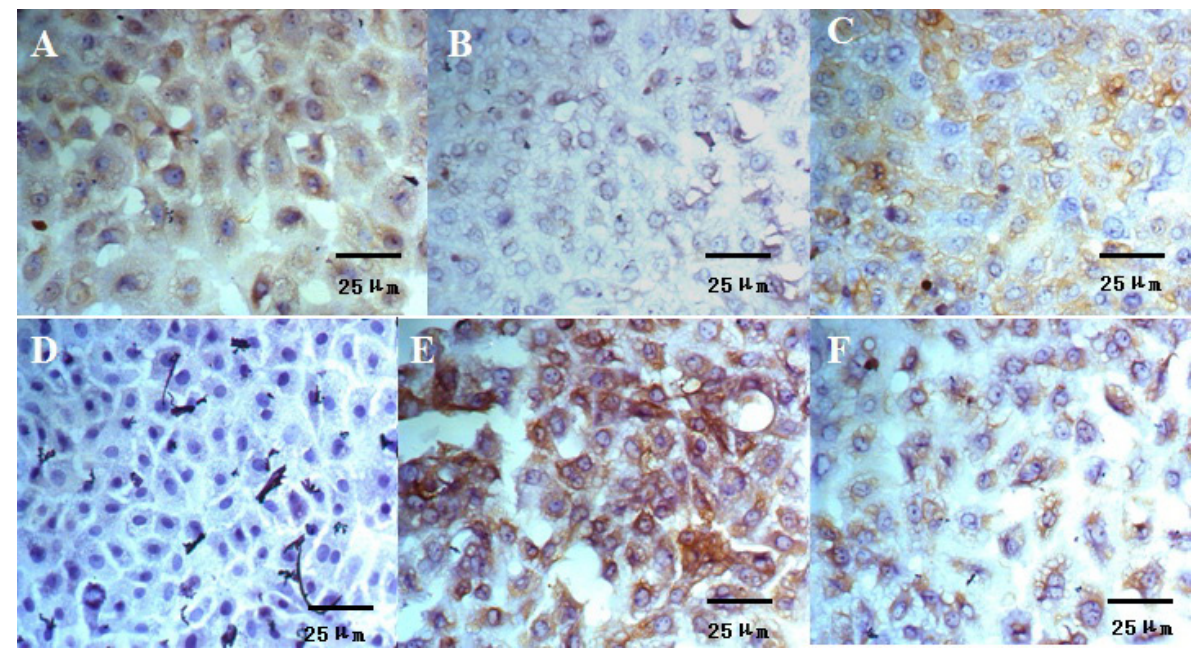

Figure 1. Immunohistochemical results of CK-18 and $\alpha$-SMA protein in NRK cells. A. CK-18 in the control group; B. CK-18 in the TGF- $\beta 1$-induced group; C. CK-18 in the TGF- $\beta 1+E G C G ~ 400 \mu \mathrm{g} / \mathrm{L}$ group; D. $\alpha$-SMA in the control group, E. $\alpha$-SMA in the TGF- $\beta 1$-induced group, F. $\alpha$-SMA in the TGF- $\beta 1+E G C G 400 \mu \mathrm{g} / \mathrm{L}$ group.

Table 3. Expression changes of Pi-Smad3 and Smad3 mRNA in NRK cytoplasm before and after EGCG intervention $(\mathrm{N}=8$, means $\pm \mathrm{SD})$.

\begin{tabular}{lcc}
\hline Group & Pi-Smad3/actin & Smad3 mRNA/GAPDH \\
\hline Control group & $0.41 \pm 0.03$ & $0.0031 \pm 0.0004$ \\
TGF- 1 -induced group & $0.87 \pm 0.05^{*}$ & $0.0122 \pm 0.0008^{*}$ \\
EGCG intervention group $(200 \mu \mathrm{g} / \mathrm{L})$ & $0.63 \pm 0.02^{*}$ & $0.0072 \pm 0.006^{*}$ \\
EGCG intervention group $(400 \mu \mathrm{g} / \mathrm{L})$ & $0.52 \pm 0.02^{*}$ & $0.0052 \pm 0.0004^{*}$ \\
\hline
\end{tabular}

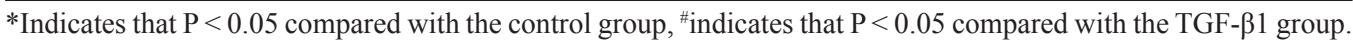

A

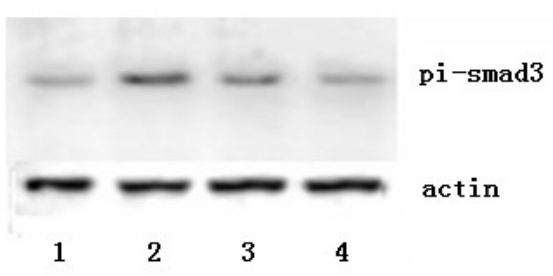

B

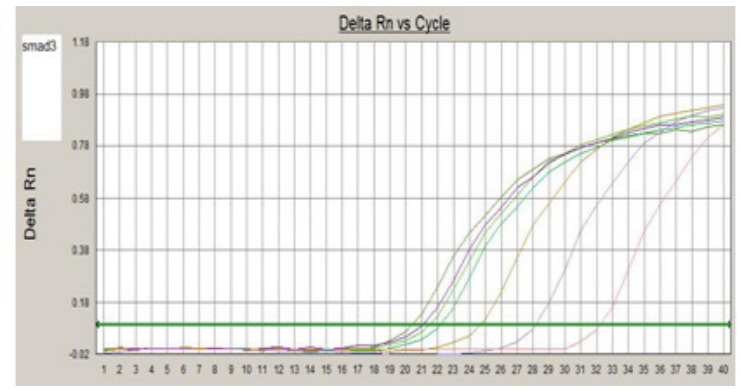

Figure 2. Western blot results of Pi-Smad3 (A) protein and RT-PCR results of Smad3 mRNA expression (B) in the NRK cytoplasm. Lane $1=$ the normal control group; lane $2=$ the TGF- $\beta 1$-induced group; lane 3 = the TGF$\beta 1+\mathrm{EGCG} 200 \mu \mathrm{g} / \mathrm{L}$ group; lane $4=$ the TGF- $\beta 1+\mathrm{EGCG} 400 \mu \mathrm{g} / \mathrm{L}$ group.

\section{Pi-ERK1/2 protein and $E R K 2$ mRNA expression in the cytoplasm of NRK cells}

After NRK cells were induced with TGF- $\beta 1$ for $48 \mathrm{~h}$, Pi-ERK1/2 protein and ERK2 
mRNA expression were significantly increased. After treatment of NRK cells with TGF- $\beta 1$ and EGCG, these changes were reduced. The effect of alleviating the proteins and mRNA expression by EGCG with concentration of $400 \mu \mathrm{g} / \mathrm{L}$ was better than that observed when using a concentration of $200 \mu \mathrm{g} / \mathrm{L}$ (Table 4 and Figure 3).

Table 4. Expression changes of Pi-ERK1/2 and ERK2 mRNA in NRK cytoplasm before and after EGCG intervention $(\mathrm{N}=8$, means $\pm \mathrm{SD})$.

\begin{tabular}{lcc}
\hline Group & Pi-ERK/actin & ERK mRNA/GAPDH \\
\hline Control group & $0.56 \pm 0.03$ & $0.0042 \pm 0.0003$ \\
TGF-1 1-induced group & $1.42 \pm 0.07^{*}$ & $0.0182 \pm 0.0007^{*}$ \\
EGCG intervention group $(200 \mu \mathrm{g} / \mathrm{L})$ & $0.85 \pm 0.03^{*}$ & $0.0071 \pm 0.0004^{*}$ \\
EGCG intervention group $(400 \mu \mathrm{g} / \mathrm{L})$ & $0.71 \pm 0.02^{*}$ & $0.0052 \pm 0.0004^{*}$ \\
\hline
\end{tabular}

*Indicates that $\mathrm{P}<0.05$ compared with the control group, ${ }^{*}$ indicates that $\mathrm{P}<0.05$ compared with the TGF- $\beta 1$ group.

$$
\mathbf{A}
$$

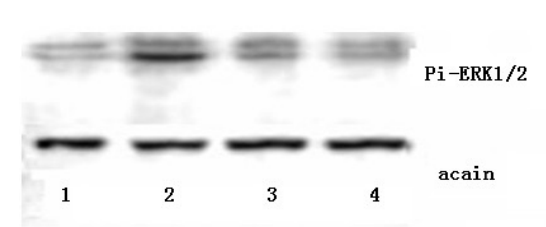

B

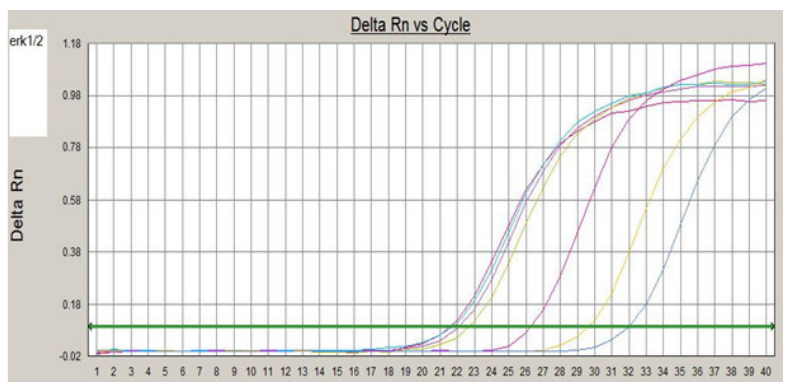

Figure 3. Western blot results of Pi-ERK1/2 protein (A) and RT-PCR results of ERK2 mRNA expression (B) in the NRK cytoplasm. Lane 1 = the normal control group; lane $2=$ the TGF- $\beta 1$-induced group; lane $3=$ the TGF$\beta 1+\mathrm{EGCG} 200 \mu \mathrm{g} / \mathrm{L}$ group; lane $4=$ the TGF- $\beta 1+\mathrm{EGCG} 400 \mu \mathrm{g} / \mathrm{L}$ group.

\section{$\beta$-catenin protein and mRNA expression in the NRK cell nucleus}

$\beta$-catenin protein expression in the TGF- $\beta 1$-induced group significantly increased compared with that in the normal group. Expression in the EGCG intervention group was lower than that in the TGF- $\beta 1$-induced group. The reduction in expression was lower in the 400 $\mu \mathrm{g} / \mathrm{L}$ EGCG intervention group compared to that of the $200 \mu \mathrm{g} / \mathrm{L}$ EGCG intervention group. $\beta$-catenin mRNA expression in the TGF- $\beta 1$-induced group was decreased compared with that in the normal group. Expression in the EGCG intervention group was higher than that in the TGF- $\beta 1$-induced group, but still lower than that in the normal group (Table 5 and Figure 4).

Table 5. Expression changes of $\beta$-catenin mRNA in NRK cytoplasm before and after EGCG intervention $(\mathrm{N}=$ 8 , means $\pm \mathrm{SD})$.

\begin{tabular}{lcc}
\hline Group & $\beta$-catenin/actin & $\beta$-catenin mRNA/GAPDH \\
\hline Control group & $0.27 \pm 0.03$ & $0.071 \pm 0.002$ \\
TGF- $\beta 1$-induced group & $0.60 \pm 0.04^{*}$ & $0.045 \pm 0.006^{*}$ \\
EGCG intervention group $(200 \mu \mathrm{g} / \mathrm{L})$ & $0.46 \pm 0.02^{\#}$ & $0.058 \pm 0.004^{\#}$ \\
EGCG intervention group $(400 \mu \mathrm{g} / \mathrm{L})$ & $0.37 \pm 0.02^{\#}$ & $0.060 \pm 0.003^{\#}$ \\
\hline
\end{tabular}

*Indicates that $\mathrm{P}<0.05$ compared with the control group, ${ }^{*}$ indicates that $\mathrm{P}<0.05$ compared with the TGF- $\beta 1$ group. 
A

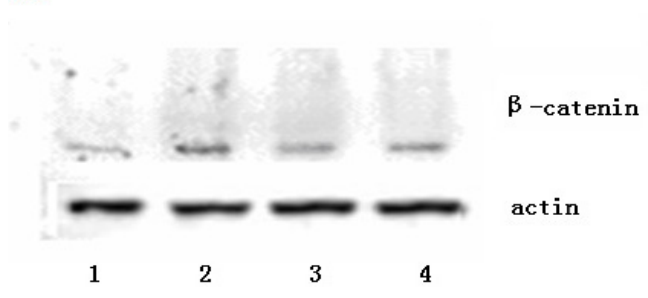

B

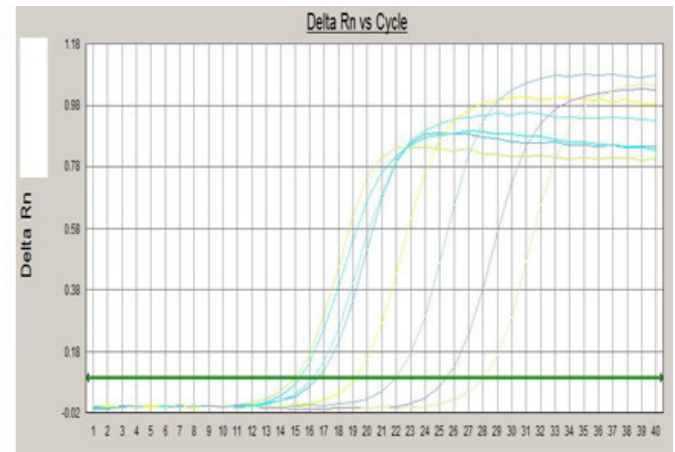

Figure 4. Western blot results of $\beta$-catenin protein $(\mathbf{A})$ and RT-PCR results of the mRNA expression $(\mathbf{B})$ in the NRK cytoplasm. Lane $1=$ the normal control group; lane $2=$ the TGF- $\beta 1$-induced group; lane $3=$ the TGF- $\beta 1+\mathrm{EGCG}$ $200 \mu \mathrm{g} / \mathrm{L}$ group; lane 4 = the TGF- $\beta 1+E G C G 400 \mu \mathrm{g} / \mathrm{L}$ group.

\section{DISCUSSION}

In this study, we found that expression of $\alpha$-SMA occurred in NRK cells after induction with TGF- $\beta 1$, while the expression of CK-18 decreased, indicating that transdifferentiation had occurred in NRK cells. These changes were reduced after intervention with EGCG, suggesting that EGCG maintained the NRK phenotype and reduced epithelial cell transdifferentiation.

TGF- $\beta 1$ is a pro-fibrotic factor that can stimulate the transformation of mesenchymal cells to epithelial cells (Rastaldi, 2006; García-Sánchez et al., 2010; Zeisberg and Duffield, 2010 ). A key signaling molecule in the TGF- $\beta 1$ signaling pathway is the cytoplasmic protein Smad. Phosphorylation kinase activity in the internal segment of the TGF- $\beta 1$ receptor membrane can phosphorylate Smad2 and Smad3 in cells as well as enhance Smad3 binding to Smad4 (Shyu et al., 2010) and promote entry of phosphorylated Smad4 into the nucleus (Shi and Massague, 2003). This regulates the target gene activity with other transcription proteins such as lymphocytes/T cell factors to cause transdifferentiation. Previous studies showed that Smad molecules are involved in TGF- $\beta 1$-induced renal interstitial fibrosis (Poncelet et al., 1999; Poncelet and Schnaper, 2001; Li et al., 2002). Complete blockage of TGF- $\beta 1 / \mathrm{Smad} 3$ signaling had a protective effect on unilateral ureteral obstruction-induced renal interstitial fibrosis (Sato et al., 2003). Phosphorylated Smad (Pi-Smad3) is the active form; in the rat model of renal interstitial fibrosis, an increase in Pi-Smad was accompanied by an increase in total Smad and its mRNA(Ning et al., 2013).

After treating NRK cells with TGF- $\beta 1$ alone for $48 \mathrm{~h}$, Pi-Smad 3 levels significantly increased. After intervention with $200 \mu \mathrm{g} / \mathrm{L}$ EGCG, Pi-Smad3 decreased, and the decrease was more significant with increasing doses of EGCG up to $400 \mu \mathrm{g} / \mathrm{L}$. This indicates that EGCG can reduce the expression of TGF- $\beta 1$-induced Pi-Smad 3 in a dose-dependent manner. mRNA changes can indirectly reflect changes in the corresponding total protein. Our PCR results showed that EGCG inhibited the transcription of Smad3 mRNA

ERK is a serine/threonine protein kinase that belongs to the mitogen-activated protein kinase (MAPK) family. Pi-ERK expression was found to be elevated in a variety of pulmonary fibrosis and liver fibrosis models, indicating that the ERK pathway is involved in the occurrence of fibrotic lesions to some extent (Robledo et al., 2000; Fubini and Hubbard, 2003; Kim et al., 2007; Cheng et al., 2013). TGF- $\beta 1$-induced fibrosis regulation was achieved by 
acetylation of Smad3 (Kim et al., 2013b). In vitro experiments have demonstrated that ERK is involved in extracellular matrix formation induced by TGF- $\beta 1$ (Mucsi et al., 1996; Ramirez et al., 2006; Hu et al., 2006). The TGF- $\beta 1$-activated kinase, which activates the MAPK pathway, links the TGF- $\beta 1$ signaling pathway with the MAPK cascade pathway. TGF- $\beta 1$-activated kinase can be activated by exogenous TGF- $\beta 1$. Important substrates of activated ERK include transcription factors such as c-myb, nuclear factor- $\mathrm{\kappa B}$, and signal transducers and activators of transcription, among others, ultimately leading to changes in the expression of fibrotic and transdifferentiated effector proteins such as type I collagen and $\alpha$-SMA.

In this study, we found that EGCG downregulated the expression of TGF- $\beta 1$-induced Pi-ERK in NRK cells in a dose-dependent manner, in agreement with previous reports demonstrating that EGCG can activate the MAPK pathway (Gao et al., 2013). Additionally, PCR results showed that EGCG also could downregulate mRNA levels of ERK in a dose-dependent manner, indicating that EGCG could reduce the expression of total ERK at the transcription level, thus coordinating inhibition of EGCG on the ERK pathway.

$\beta$-catenin is a multifunctional protein, and $\beta$-catenin can bind to E-cadherin to form E$\mathrm{cad} / \beta$-cat complexes, thereby maintaining the polarity of normal epithelial cells and adhesion between cells (Drees et al., 2005). Free $\beta$-catenin entered into the nucleus when E-cadherin decreased to bind to transcription factor lymphocytes/T cell factor family members as signaling molecules involved in cell proliferation and migration (Gottardi and Gumbiner, 2004). We found that EGCG reduced the expression of TGF- $\beta 1$-induced $\beta$-catenin in the nucleus in a dose-dependent manner. The PCR results showed that this effect was not caused by a reduction in $\beta$-catenin transcription; in fact, the transcription level in the EGCG intervention group was higher than that in the TGF- $\beta 1$ group, indicating that EGCG can increase expression of $\beta$-catenin to maintain the epithelial phenotype and inhibit nuclear translocation of $\beta$-catenin and its signaling.

The mechanism of EGCG on Pi-ERK, Pi-Smad3, $\beta$-catenin, and their mRNA is unknown, but may occur through 2 mechanisms: 1) EGCG may affect redox signal transduction. Reactive oxygen species spread signals by modifying the mercapto group or the heme iron in the active sites of target molecules that are modified by a redox reaction (Burdon, 1995; Iuchi and Weiner, 1996; Rhee, 1999; Barrett et al., 1999). Experimental results showed that the generation of reactive oxygen species was closely related to the process of ERK phosphorylation (Katiyar et al., 2001; Zhang et al., 2006). 2) EGCG affected intracellular signal transduction by trapping effects for some of the growth factor ligands (Weber et al., 2004), and indirectly influenced the ERK and Smad pathways through crosstalk among a variety of intracellular signal pathways. However, the exact mechanism requires further experimental validation.

\section{REFERENCES}

Barrett WC, DeGnore JP, Keng YF, Zhang ZY, et al. (1999). Roles of superoxide radical anion in signal transduction mediated by reversible regulation of protein-tyrosine phosphatase 1B. J. Biol. Chem. 274: 34543-34546.

Burdon RH (1995). Superoxide and hydrogen peroxide in relation to mammalian cell proliferation. Free Radic. Biol. Med. 18: 775-794.

Cheng X, Gao W, Dang Y, Liu X, et al. (2013). Both ERK/MAPK and TGF-Beta/Smad signaling pathways play a role in the kidney fibrosis of diabetic mice accelerated by blood glucose fluctuation. J. Diabetes Res. 2013: 463740.

Drees F, Pokutta S, Yamada S, Nelson WJ, et al. (2005). Alpha-catenin is a molecular switch that binds E-cadherin-betacatenin and regulates actin-filament assembly. Cell 123: 903-915.

Fubini B and Hubbard A (2003). Reactive oxygen species (ROS) and reactive nitrogen species (RNS) generation by silica 
in inflammation and fibrosis. Free Radic. Biol. Med. 34: 1507-1516.

Gao Y, Li W, Jia L, Li B, et al. (2013). Enhancement of (-)-epigallocatechin-3-gallate and theaflavin-3-3'-digallate induced apoptosis by ascorbic acid in human lung adenocarcinoma SPC-A-1 cells and esophageal carcinoma Eca-109 cells via MAPK pathways. Biochem. Biophys. Res. Commun. 438: 370-374.

García-Sánchez O, López-Hernández FJ and López-Novoa JM (2010). An integrative view on the role of TGF-beta in the progressive tubular deletion associated with chronic kidney disease. Kidney Int. 77: 950-955.

Gottardi CJ and Gumbiner BM (2004). Distinct molecular forms of beta-catenin art targeted to adhesive or transcriptional complexes. J. Cell Boil. 167: 339-349.

Hu Y, Peng J, Feng D, Chu L, et al. (2006). Role of extracellular signal-regulated kinase, p38 kinase, and activator protein-1 in transforming growth factor-beta1-induced alpha smooth muscle actin expression in human fetal lung fibroblasts in vitro. Lung 184: 33-42.

Iuchi S and Weiner L (1996). Cellular and molecular physiology of E. coli in the adaption to aerobic environment. $J$. Biochem. 120: 1055-1063.

Katiyar SK, Afaq F, Azizuddin K and Mukhtar H (2001). Inhibition of UVB-induced oxidative stress-mediated phosphorylation of mitogen-activated protein kinase signaling pathways in cultured human epidermal keratinocytes by green tea polyphenol (-)-epigallocatechin-3-gallate. Toxicol. Appl. Phamacol. 176: 110-117.

Kim CS, Kim JM, Nam SY, Yang KH, et al. (2007). Low-dose of ionizing radiation enhances cell proliferation via transient ERK1/2 and p38 activation in normal human lung fibroblasts. J. Radiat. Res. 48: 407-415.

Kim MK, Maeng YI, Sung WJ, Oh HK, et al. (2013a). The differential expression of TGF-ß1, ILK and wnt signaling inducing epithelial to mesenchymal transition in human renal fibrogenesis: an immunohistochemical study. Int. J. Clin. Exp. Pathol. 6: 1747-1758.

Kim S, Lim JH and Woo CH (2013b). ERK5 inhibition ameliorates pulmonary fibrosis via regulating Smad3 acetylation. Am. J. Pathol. 183: 1758-1768.

Li JH, Zhu HJ, Huang XR, Lai KN, et al. (2002). Smad7 inhibits fibrotic effect of TGF-Beta on renal tubular epithelial cells by blocking Smad2 activation. J. Am. Soc. Nephrol. 13: 1464-1472.

Liu SF, Chang SY, Lee TC, Chuang LY, et al. (2012). Dioscorea alata attenuates renal interstitial cellular fibrosis by regulating Smad- and epithelial-mesenchymal transition signaling pathways. PLoS One 7: e47482.

Liu Y (2010). New insights into epithelial-mesenchymal transition in kidney fibrosis. J. Am. Soc. Nephrol. 21: 212-222.

Mucsi I, Skorecki KL and Goldberg HJ (1996). Extracellular signal regulated kinase and the small GTP-binding protein, rac, contribute to the effects of transforming growth factor-beta1 on gene expression. J. Biol. Chem. 271: 16567-16572.

Nakamuta M, Higashi N, Kohjima M, Fukushima M, et al. (2005). Epigallocatechin-3-gallate, a polyphenol component of green tea, suppresses both collagen production and collagenase activity in hepatic stellate cells. Int. J. Mol. Med. 16: 677-681.

Ning XH, Ge XF, Cui Y and An HX (2013). Ulinastatin inhibits unilateral ureteral obstruction-induced renal interstitial fibrosis in rats via transforming growth factor $\beta$ (TGF- $\beta$ )/Smad signalling pathways. Int. Immunopharmacol. 15: 406-413.

Poncelet AC and Schnaper HW (2001). Sp1 and Smad proteins cooperate to mediate transforming growth factor-beta 1-induced alpha 2(I) collagen expression in human glomerular mesangial cells. J. Biol. Chen. 276: 6983-6992.

Poncelet AC, de Casetecker MP and Schnaper HW (1999). The transforming growth factor-beta/SMAD Signaling pathway is present and functional in human mesangial cells. Kidney Int. 56: 1354-1365.

Ramirez AM, Shen Z, Ritzenthaler JD and Roman J (2006). Myofibroblast transdifferentiation in obliterative bronchiolitis: tgf-beta signaling through smad3-dependent and -independent pathways. Am. J. Transplant. 6: 2080-2088.

Rastaldi MP (2006). Epithelial-mesenchymal transition and its implications for the development of renal tubulointerstitial fibrosis. J. Nephrol. 19: 407-412.

Rhee SG (1999). Redox signaling: Hydrogen peroxide as intracellular messenger. Exp. Mol. Med. 31: 53-59.

Robledo RF, Buder-Hoffmann SA, Cummins AB, Walsh ES, et al. (2000). Increased phosphorylated extracellular signal regulated kinase immunoreactivity associated with proliferative and morphologic lung alterations after chrysotile asbestos inhalation in mice. Am. J. Pathol. 156: 1307-1316.

Sato M, Muragaki Y, Saika S, Roberts AB, et al. (2003). Targeted disruption of TGF- $\beta$ 1/Smad3 signaling protects against renal tubulointerstitial fibrosis induced by unilateral ureteral obstruction. J. Clin. Invest. 112: 1486-1494.

Shi Y and Massague J (2003). Mechanisms of TGF-beta signaling from cell membrane to the nucleus. Cell 113: 685-700.

Shyu KG, Wang BW, Chen WJ, Kuan P, et al. (2010). Mechanism of the inhibitory effect of atorvastatin on endoglin expression induced by transforming growth factor-beta1 in cultured cardiac fibroblasts. Eur. J. Heart Fail. 12: 219-226.

Weber AA, Neuhaus T, Skach RA, Hescheler J, et al. (2004). Mechanisms of the inhibitory effects of epigallocatechin-3 gallate on platelet-derived growth factor-BB-induced cell signaling and mitogenesis. FASEB J. 18: 128-130.

Xiao J, Ho CT, Liong EC, Nanji AA, et al. (2013). Epigallocatechin gallate attenuates fibrosis, oxidative stress, and 
inflammation in non-alcoholic fatty liver disease rat model through TGF/SMAD, PI3 K/Akt/FoxO1, and NF-kappa B pathways. Eur. J. Nutr. 53: 187-199.

Yumei F, Zhou Y, Zheng S and Chen A (2006). The antifibrogenic effect of (-)-epigellocatechin gallate results from the induction of de novo synthesis of glutathione in passaged rat hepatic stellate cells. Lab. Invest. 86: 697-709.

Zeisberg M and Duffield JS (2010). Resolved: EMT produces fibroblasts in the kidney. J. Am. Soc. Nephrol. 21: 12471253 .

Zhang W, Wang Y, Chen CW, Xing K, et al. (2006). The positive feedback role of arachidonic acid in the platelet-derived growth factor-induced signaling in lens epithelial cells. Mol. Vis. 12: 821-831.

Zhen MC, Wang Q, Huang XH, Cao LQ, et al. (2007). Green tea polyphenol epigallocatechin-3-gallate inhibits oxidative damage and preventive effects on carbon tetrachloride-induced hepatic fibrosis. J. Nutr. Biochem. 18: 795-805. 